\title{
Inflammatory biomarkers in patients with sciatica: a systematic review
}

\author{
Maarten J. Jungen ${ }^{1}$, Bastiaan C. ter Meulen ${ }^{1,2^{*}}$, Tim van Osch ${ }^{1}$, Henry C. Weinstein ${ }^{1,2}$ and \\ Raymond W. J. G. Ostelo 3,4
}

\begin{abstract}
Background: This systematic review focusses on inflammation as an underlying pathogenic mechanism in sciatica. We addressed two questions in particular: (1) what inflammatory biomarkers have been identified in patients with sciatica in the literature so far? 2) is there an association between the level of inflammatory activity and clinical symptoms?
\end{abstract}

Methods: The search was conducted up to December 19th 2018 in MEDLINE, EMBASE, CENTRAL and Web of Science. The study selection criteria: (1) observational cohort studies, cross-sectional studies and randomized clinical trials (RCT), (2) adult population ( $\geq 18$ years) population with sciatica, (3) concentrations of inflammatory biomarkers measured in serum, cerebrospinal fluid (CSF) or biopsies, and (4) evaluation of clinically relevant outcome measures (pain or functional status). Three reviewers independently selected studies and extracted data regarding the study characteristics and the outcomes. Risk of Bias was evaluated using an adjusted version of the Quality in Prognosis Studies (QUIPS) tool.

Results: In total 16 articles fulfilled the criteria for inclusion: 7 cross sectional observational studies and 9 prospective cohort studies that included a total of 1212 patients. With regard to question 1) the following markers were identified: interleukin (IL)-1 $\beta$, IL-2, IL-4, IL-6, IL-8, IL-10, IL-17, IL-21, tumor necrosis factor-a (TNF-a), phospholipase A2, high sensitivity C-reactive protein (hsCRP), C-X-C motif chemokine 5 (CXCM5), CX3CL1, CCL2, epidermal growth factor (EGF), and monocyte chemotactic protein 4 (MCP-4). With regard to question 2) several positive correlations were found in longitudinal studies: a strong positive correlation between inflammatory mediators or byproducts and pain (measured by visual analogue scale, VAS) was found for IL-21 in two studies ( $r>0,8)$, and moderate positive correlations for TNF-a in both serum $(r=0,629)$ and biopsy $(r=0.65)$; severe pain (VAS $>4)$ is associated with increased hsCRP levels among patients with sciatica (adjusted $\mathrm{OR}=3.4(95 \% \mathrm{Cl}, 1.1$ to 10$)$.

Conclusion: In this systematic review there was considerable heterogeneity in the type of biomarkers and in the clinical measurements in the included studies. Taking into account the overall risk of bias of the included studies there is insufficient evidence to draw firm conclusions regarding the relationship between inflammation and clinical symptoms in patients with sciatica.

Keywords: Systematic review, Sciatica, Lumbar disc herniation, Inflammation, Biomarkers, Cytokines, Interleukin

\footnotetext{
* Correspondence: bas.termeulen@olvg.nl

'Department of Neurology, OLVG, Amsterdam, The Netherlands

2Department of Neurology, Zaans Medisch Centrum, Zaandam, The

Netherlands

Full list of author information is available at the end of the article
}

(C) The Author(s). 2019 Open Access This article is distributed under the terms of the Creative Commons Attribution 4.0 International License (http://creativecommons.org/licenses/by/4.0/), which permits unrestricted use, distribution, and reproduction in any medium, provided you give appropriate credit to the original author(s) and the source, provide a link to the Creative Commons license, and indicate if changes were made. The Creative Commons Public Domain Dedication waiver (http://creativecommons.org/publicdomain/zero/1.0/) applies to the data made available in this article, unless otherwise stated. 


\section{Background}

Sciatica or lumbosacral radicular syndrome is characterized by pain radiating into the leg along the course of one of the lumbar nerve roots [1]. Sometimes there is numbness or tingling in the dermatomal distribution of a nerve root. Paresis is present almost half of patients, for example weakness of plantar flexion in S1 radiculopathy. Most patients experience back pain also. The incidence of sciatica in The Netherlands is 9.4 cases per 1000 adults per year [2]. Sciatica is a major cause of costs of hospital care and costs resulting from absenteeism from work [3].

Sciatica is considered having different pathogenic components. First, there is a mechanic component that consists of compression of the nerve root by a herniated disc. Neuroradiologic studies confirm that approximately $90 \%$ of cases of sciatica are associated with a disc disorder [4, 5]. Second, it has been hypothesized that inflammation may play a role in patients with low back pain [6] and sciatica [7], the elderly in particular [8] A range of proand anti-inflammatory proteins has been found in serum, CSF and biopsies of patients with sciatica, including interleukin (IL)-1 $\beta$, IL-6, IL-8 and tumor necrosis factor (TNF)- $\alpha$ [7]. Third, in patients with sciatica there possibly is also a neuropathic component caused by neural damage at the level of the nerve root [9].

In this systematic review we focus on the role that inflammation may play in lumbosacral radicular syndrome. We conducted this review as an inflammatory substrate in patients with sciatica could be a potential target for anti-inflammatory therapy, specifically non-steroidal antiinflammatory drugs (NSAIDs) or transforaminal epidural corticosteroids. We address two questions in particular: (1) what inflammatory biomarkers have been identified in patients with sciatica 2) Is there an association between the level of inflammatory activity and clinical symptoms?

\section{Methods}

\section{Criteria for inclusion and exclusion}

A study must fulfill the following inclusion criteria to be included in this review:

\section{Types of studies}

Observational cohort studies (with and without control group), cross-sectional studies and randomized clinical trials (RCT). Studies should contain both laboratory and clinical information. Animal studies were excluded.

\section{Types of participants}

Adults, older than 18 years, with sciatica. Inflammatory activity is measured in serum, cerebrospinal fluid (CSF) or in tissues obtained through biopsy.

\section{Types of outcome measures}

For question 1) regarding the presence of biomarkers, the primary outcome was presence of inflammatory proteins in serum, biopsies or CSF. There was no restriction to laboratory methods, including ELISA and Western Blotting for serum and CSF, and messenger RNA qualitative polymerase chain reaction (mRNA qPCR) for biopsy studies.

For question 2) regarding clinical features, the outcomes were pain and physical functional status. The following self-reported outcome measures were assessed: pain intensity (e.g. visual analogue scale (VAS)), back-specific disability (e.g. Roland Morris, Oswestry Disability Index), and perceived recovery (e.g. overall improvement).

\section{Search methods}

A systematic literature review was performed according to the Preferred Reporting Items for Systematic Reviews and Meta-Analysis (PRISMA)-statement [10]. Studies were identified by searching PubMed, Embase.com, Cochrane Central Register of Controlled Trials/Wiley and Web of Science/Clarivate Analytics from inception up to 19 December 2018. The following concepts, including synonyms and closely related words, were used as index terms or free-text words: 'sciatica,' 'inflammation' and 'cytokines'.

The full search strategy for all databases can be seen in Additional file 1. References of retrieved articles and relevant overview articles were checked to identify additional studies.

\section{Methods of review Study selection}

Three authors (MJ/BTM/TVO) independently screened the abstracts and titles retrieved by the search strategy and applied the inclusion criteria. Duplicate articles were excluded. Full texts were obtained if the abstract fulfilled the inclusion criteria and were subsequently screened on inclusion criteria by the authors, independently following the PRISMA guidelines. The checklist can be seen in Additional file 2. Any disagreements between the authors were resolved by discussion and consensus.

\section{Risk of bias assessment}

Two authors (MJ and TVO) independently conducted the risk-of-bias assessment. Risk of Bias (ROB) was evaluated using the Quality in Prognosis Studies (QUIPS) tool [11]. The reason to choose for QUIPS is that in this review we included observational studies assessing the (longitudinal) association between the level of inflammatory activity and clinical symptoms. This resembles very closely a prognostic model and therefore we used the QUIPS tool that supports a systematic appraisal of such studies. It is based on recommendations from a comprehensive review of quality assessment in prognosis systematic reviews and is informed by basic epidemiologic 
principles. Independently developed and modified versions of the tool have been successfully used by several research groups, with moderate to substantial interrater reliability.

The QUIPS tool considers the following 6 domains of bias: (1) bias due to patient selection (2) attrition, (3) prognostic factor measurement, (4) outcome measurement, (5) study confounding (6) statistical analysis and reporting. Items and operationalization are given in Additional file 3. Due to the explorative nature of this review, only the first four domains were included in the risk of bias assessment. The items of these four domains were each scored to assess the overall risk of bias of the included study. For each item within a domain the responses can be: 'yes', 'partial', 'no' or 'unsure'. The responses on these items were combined to assess the risk of bias per domain. The risk of bias for each domain was scored as 'high' $(+)$, 'moderate' $(+/-)$ or 'low' (-) risk of bias. In line with Den Bakker et al. [12], a study was considered to be of low overall risk of bias when the domain scores were rated as low or moderate on all of the 4 domains, with at least 2 rated as low (including the outcome measurement domain). We scored a study as having high overall risk of bias if 2 or more of the domains were judged as high. A study was scored as moderate if the criteria for 'low' or 'high' were not met. Low overall risk of bias implies that the associations found in this study are unlikely to be different for participants and eligible nonparticipants, not to be different for completing and non completing participants, not to be different for different levels of the outcome of interest, and unlikely to be different related to the baseline level of the prognostic factor [11].

\section{Data extraction}

Data were extracted independently by two review authors (M), TVO). The following data were extracted: (1) characteristics of the studies: number of participants, gender, age; (2) characteristics of inflammatory activity (what biomarkers and how they were measured); (3) characteristics of the outcomes: outcome measures, instruments, and scores (e.g. mean, median, standard deviation, and confidence interval). Any disagreements were discussed between the two authors and a third review author (BTM) was consulted if necessary.

\section{Data analysis and statistics}

Due to the heterogeneous data our approach was merely descriptive. For question 1) regarding the presence of biomarkers the type and material (serum/CSF/biopsy) were extracted. For question 2) the measures of association that were presented in the included papers were extracted. For example, the correlation between pain measured by a VAS score and biomarker expression. We present the results of the cross-sectional studies and the longitudinal studies separately. In terms of interpretation we used the following guidance: a correlation coefficient of -1 or +1 indicates a perfect linear relation [13]. When Odds Ratio's (OR) were presented these were extracted, including the $p$-value or the $95 \% \mathrm{CI}$ and the magnitude of the OR was interpreted as follows: $\mathrm{OR}=$ $1.68,3.47$, and 6.71 are equivalent to Cohen's $d=0.2$ (small), 0.5 (medium), and 0.8 (large) [14]. For other measures of association the p-value was used to assess if the association was statistically significant.

\section{Results}

\section{Description of studies}

The electronic search initially yielded 3761 articles: 980 in PubMed, 1435 in EMBASE, 41 in CENTRAL and 1305 in Web of Science. After de-duplication 2076 articles were left. Of these, 948 were excluded. The main reasons for exclusion were use of animals or conference abstracts. One study by Schistadt et al. [15] was identified through the reference list of Pedersen et al. [26]. Eventually 19 articles fulfilled the criteria for inclusion, of which 16 were analyzed and 3 were excluded. The 16 studies that were analyzed consisted of 7 cross sectional observational studies [16-22] and 9 prospective cohort studies [15, 23-30]. The studies of Kraychete et al., Weber et al. and Miao et al. were excluded because clinical information was lacking [31] or no correlation between biomarkers and clinical outcomes was described [32, 33]. The analyzed studies included a total number of 1212 patients. For overview see flowchart (Fig. 1).

\section{Risk of Bias (RoB) assessment}

The results of the risk of bias assessment are shown in Table 1. Of the cross sectional studies classified as low overall risk of bias [21, 22], and 5 were classified as moderate risk of bias [16-20], mainly due to inadequate participation $[16,17]$ or moderate outcome reporting $[15,16,18,19]$.

Of the longitudinal studies, 5 were classified as low high quality [14] risk of bias [15, 23, 27-29] and four were considered as moderate risk of bias [24, 25, 23, 29] mainly due to inadequate participation $[25,26]$ or high number of drop outs (attrition) [2].

\section{Biomarkers}

The following biomarkers were examined, most of them cytokines (12 of 17 studies): interleukin-1 $\beta$ (IL-1 $\beta$ ) [21, 26], interleukin-2 (IL-2) [21], interleukin 4 (IL-4) $[21,30]$, interleukin-6 (IL-6) [14, 21, 25-27], interleukin-8 (IL-8) [17, 21, 26, 27], interleukin-10 (IL-10) [21, 27], interleukin-17 (IL-17) [19], interleukin-21 (IL-21) [30]. Palada et al. studied a biomarker panel including TNF, interferon-gamma (INFg), IL-1b, IL-2, IL-4, IL-6, IL-8, IL-10, IL-12p70, IL-13 and monocyte chemotactic protein 


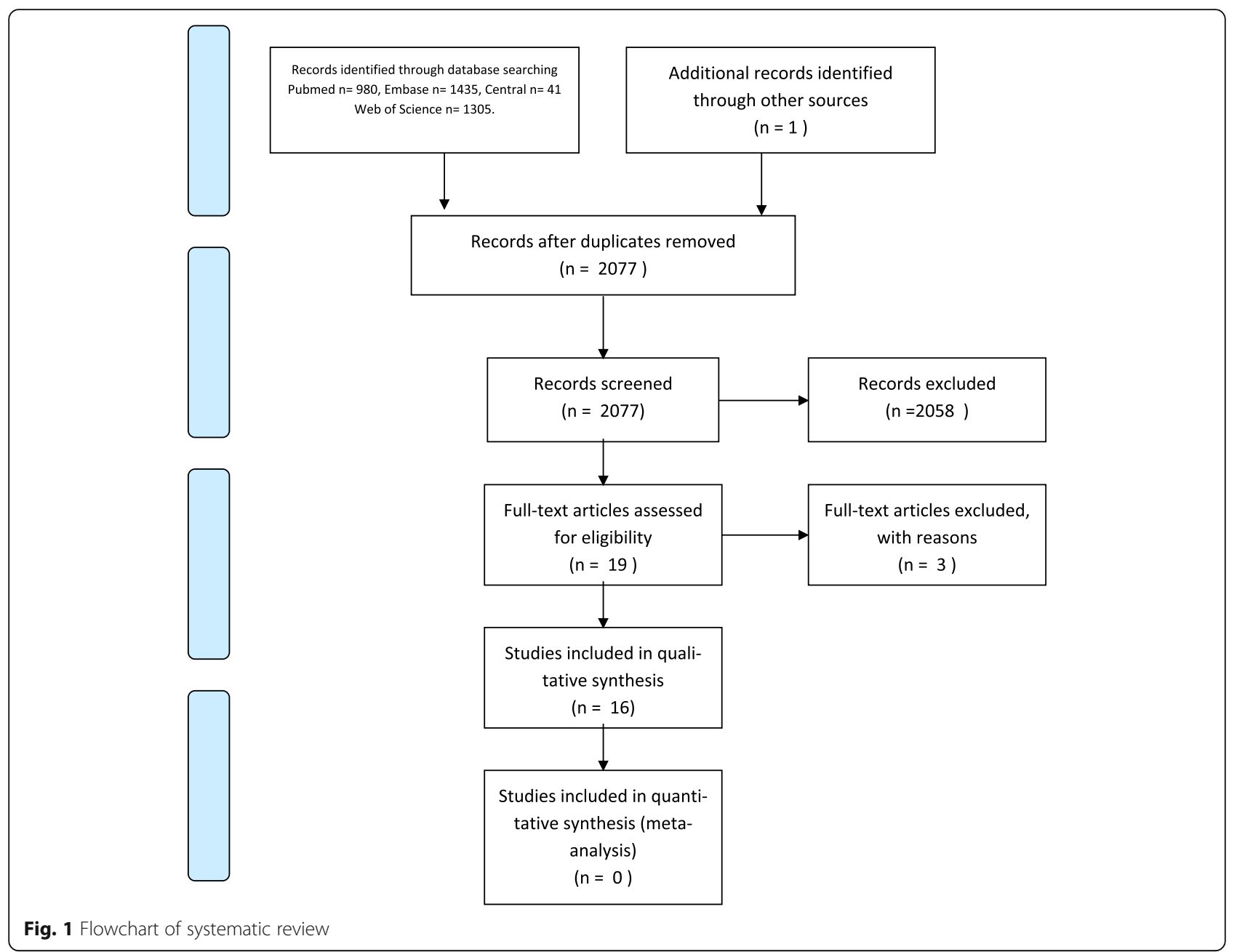

1 (MCP1) [21]. Three studies measured tumor necrosis factor- $\alpha$ (TNF- $\alpha)[25,28,20]$ and one study looked for phospholipase A2 [16]. Sturmer et al. and Sugimori et al. measured levels of high sensitivity C-reactive protein (hsCRP), a sensitive marker of low grade systemic inflammation [18, 23]. Peng et al. looked for expression of the chemokines CX3CL1 and CCL2 [21]. Moen et al. measured 92 different pro and anti-inflammatory cytokines the results of which they compiled in an composite inflammation score [28]: 13 were significantly upregulated, including C-X-C motif chemokine 5 (CXCM5; $217 \%$ increase), epidermal growth factor (EGF; $142 \%$ increase), and monocyte chemotactic protein 4 (MCP-4; $70 \%$ increase).

Thirteen studies measured inflammatory activity in serum [15-23, 26-29], four used biopsies of the nucleus pulposus (NP) [20, 24, 25], annulus fibrosus (AF) $[24,25]$ and ligamentum flavum (LF) [24]. Two studies used CSF for analysis [17, 22]. The following techniques were used: ELISA [15, 17, 19, 26, 27, 29], mRNA/ qPCR $[20,22,24]$, proximal extension assay (PEA) [28], Western
Blotting $[21,30]$. The two hsCRP studies used latex agglutination $[18,23]$.

\section{Clinical features in relationship to biomarkers}

Tables 2 and 3 summarize the duration of symptoms, age), type of marker and sampling, the clinical parameters and associations between biomarkers and clinical parameters that were found. We distinguished between cross sectional studies (Table 2) and longitudinal studies (Table 3) studies.

All studies included patients who suffered from sciatica for more than 3 months (average), and therefor had chronic low back pain. All studies reported VAS (Visual analog scale) as assessment tool for pain, except Sugimori et al. and Wang et al. $[18,27]$. Piperno et al. also used the Dallas Pain Questionnaire [16]. Pain duration at baseline was described precisely in 2 of the cross sectional studies $[17,21]$ and 4 of the longitudinal studies $[15,26,27,29]$. Wang et al, determined functioning using the Oswestry Disability Index (ODI) and also used the short form-36 (SF-36) questionnaire [27]. Sugimori et al. and Peng et al. also used the Japanese Orthopedic Association Score for 
Table 1 Results of risk of bias assessment using the adjusted QUIPS-tool

\begin{tabular}{|c|c|c|c|c|c|}
\hline \multicolumn{6}{|c|}{ Cross sectional studies } \\
\hline & Participation & Attrition & Prognostic Factor & Outcome & $\begin{array}{l}\text { Risk of bias: } \\
+=\text { high } \\
+/-=\text { moderate } \\
-=\text { low }\end{array}$ \\
\hline Piperno 1997 [16] & Moderate & Moderate & Low & Moderate & $+/-$ \\
\hline Brisby [17] & High & Low & Low & Moderate & $+/-$ \\
\hline Sugimori [18] & High & Low & Moderate & Low & $+/-$ \\
\hline Cheng [19] & Moderate & Low & Low & Moderate & $+/-$ \\
\hline Xue [20] & Moderate & Low & Low & Moderate & $+/-$ \\
\hline Peng [21] & Moderate & Low & Moderate & Low & - \\
\hline Palada [22] & Low & Low & Low & Low & - \\
\hline \multicolumn{6}{|l|}{ Longitudinal studies } \\
\hline Schistadt [15] & Low & Moderate & Low & Low & - \\
\hline Stürmer [23] & Low & Moderate & Low & Low & - \\
\hline Andrade [24] & High & Low & Low & Moderate & $+/-$ \\
\hline Andrade [25] & High & Low & Low & Moderate & $+/-$ \\
\hline Pedersen [26] & Low & High & Low & Moderate & $+/-$ \\
\hline Wang [27] & Low & Low & Low & Moderate & - \\
\hline Moen [28] & Low & Moderate & Low & Low & - \\
\hline Zu [29] & Low & Moderate & Low & Low & - \\
\hline Chen [30] & Moderate & Moderate & Low & Moderate & $+/-$ \\
\hline
\end{tabular}

overall functioning. ${ }^{187,21}$ Most of the associations between markers and clinical symptoms, were found in the serum studies using ELISA techniques.

For the cross sectional studies a strong positive correlation was found between IL-21 and VAS for pain in one study $(r=0,809$ [20]. A moderate positive correlation was found for MCP-1 in serum $(r=0,659)$ [22] and
hsCRP in serum $(r=0,538)$ [18]. The moderate negative correlation between the JOA score and hsCRP. should be explained positively as a high JOA score implies better clinical functioning.

For the longitudinal studies a strong positive correlation was found between Il-21 and VAS for pain in one study $(r=0,834)$ [30]. A moderate positive correlation

Table 2 Inflammatory biomarkers in relationship to clinical features (cross sectional studies)

\begin{tabular}{|c|c|c|c|c|c|c|c|}
\hline Study & Age (yr) & Duration (months) & Source & Technique & Marker & Clin O & Ass \\
\hline Piperno [16] & $40+-13$ & $20+-26$ & serum & Degradation & PhosA2 & VAS & no \\
\hline Brisby [17] & N & $92(5-390)^{a}$ & serum CSF & ELISA & $\|-8$ & VAS & $r=-0,48$ \\
\hline Sugimor [18] & $26.4(16-39)$ & N & serum & Latex agl & hsCRP & $\mathrm{JOA}$ & $r=-0,583$ \\
\hline Cheng [19] & $44(30-72)$ & N & serum & ELISA & $\|-17$ & VAS & $r=0,458$ \\
\hline Xue [20] & $52(21-70)$ & $\mathrm{N}$ & serum NP Biopsy & mRNA qPCR & $\|-21$ & VAS & $r=0,809$ \\
\hline \multirow[t]{4}{*}{ Peng [21] } & \multirow[t]{4}{*}{$34.2(+-5.8)^{\mathrm{b}}$} & \multirow[t]{4}{*}{$4.5(1-22)$} & serum & Western blot & CX3CL1 & VAS & $r=0,393$ \\
\hline & & & serum & Western blot & CX3CL1 & $\mathrm{JOA}$ & $r=-0,342$ \\
\hline & & & serum & Western blot & CCL2 & VAS & $r=0,360$ \\
\hline & & & serum & Western blot & CCL2 & $\mathrm{JOA}$ & $r=-0,375$ \\
\hline \multirow[t]{3}{*}{ Palada [22] } & \multirow[t]{3}{*}{$41.13(15-65)$} & \multirow[t]{3}{*}{$>1$ month } & serum & mRNA qPCR & $\|-6$ & VAS & $r=0,380$ \\
\hline & & & CSF & mRNA qPCR & $\|-8$ & VAS & $r=0,395$ \\
\hline & & & serum & mRNA qPCR & MCP1 & VAS & $r=0,515$ \\
\hline
\end{tabular}

Ass association, Clin O clinical outcome, CSF cerebrospinal fluid, ELISA enzyme linked serum assay, IL interleukin, JOA Japanese orthopedic association score, Latex agl latex agglutination, NP nucleus pulposus, $q P C R$ quantitative polymerase chain reaction, $V A S$ visual analogue scale, $Y r$ years

adays

${ }^{\mathrm{b}} \mathrm{VAS}>7$ 
Table 3 Inflammatory biomarkers in relationship to clinical features (longitudinal studies)

\begin{tabular}{|c|c|c|c|c|c|c|c|}
\hline Study & Age (yr) & Duration (weeks) & Source & Technique & Substance & Clin $\mathrm{O}$ & Ass \\
\hline Schistad [15] & $41.3(10)$ & $20.3(19.9)$ & serum & ELISA & $11-6$ & VAS & $B=0,64^{a}$ \\
\hline Sturmer [23] & $44.8(12.4)$ & acute $^{b}$ & serum & latex agl & hsCRP & VAS $>4$ & $\mathrm{aOR}=3,4^{\mathrm{c}}$ \\
\hline \multirow[t]{3}{*}{ Andrade [24] } & 49 & N & NP Biopsy & mRNA qPCR & TNFa & VAS & $r=0,65$ \\
\hline & & & AF Biopsy & mRNA qPCR & TNFa & VAS & $r=0,06$ \\
\hline & & & LF Biopsy & mRNA qPCR & TNFa & VAS & $r=0,29$ \\
\hline \multirow[t]{4}{*}{ Andrade [25] } & 41 & $13-26$ & NP Biopsy & mRNA qPCR & IL-6 & VAS & $r=0,23$ \\
\hline & & & NP Biopsy & mRNA qPCR & $I L-1 b$ & VAS & $r=0,05$ \\
\hline & & & NP Biopsy & mRNA qPCR & IL-6 & VAS & $r=-0,11$ \\
\hline & & & NP Biopsy & mRNA qPCR & IL-1b & VAS & $r=0,03$ \\
\hline \multirow[t]{2}{*}{ Pedersen [26] } & $39.3(18-58)$ & $32.3+-4.5$ & serum & ELISA & IL-6 & VAS & $F(1.0,118)=9,7$ \\
\hline & & & serum & ELISA & IL-8 & VAS & $F(1.0,118,0)=6,9$ \\
\hline \multirow[t]{4}{*}{ Wang [27] } & $37+-13.3)^{d}$ & $48(+-29)$ & serum & ELISA & IL-6 & ODI & $r=0,394$ \\
\hline & & & serum & ELISA & TNFa & ODI & $r=0,629$ \\
\hline & & & serum & ELISA & IL-10 & ODI & $r=0,415$ \\
\hline & & & serum & ELISA & IL-8 & ODI & $r=-0,133$ \\
\hline Moen [28] & $40(9)$ & $>8$ & serum & PEA & inflammation score & VAS & positive Linear discriminant analysis \\
\hline \multirow[t]{4}{*}{ Zu [29] } & $34.0+-12.3^{e}$ & $48(+-29)^{c}$ & serum & ELISA & TNFa & $O D I+V A S>3$ & $r=0,2$ \\
\hline & & & serum & ELISA & TNFa & $\mathrm{ODI}+\mathrm{VAS}<3$ & $r=0,37$ \\
\hline & & & serum & ELISA & IL-4 & $\mathrm{ODI}+\mathrm{VAS}>3$ & $r=0,09$ \\
\hline & & & serum & ELISA & IL-4 & $\mathrm{ODI}+\mathrm{VAS}<3$ & $r=0,08$ \\
\hline Chen [30] & $51.3+-24.4$ & N & NP biopsy & Western blot & $\mathrm{IL}-21$ & VAS & $r=0.834$ \\
\hline
\end{tabular}

$A F$ annulus fibrosus, $a O R$ adjusted Odds Ratio, Ass association, Clin $O$ clinical outcome, $L F$ ligamentum flavum, ELISA enzyme linked immune assay, $h$ sCRP high sensitive c-reactive protein, II interleukin, latex agl latex agglutination, $m R N A$ messenger RNA, N unknown, NP nucleus pulposus, ODI Oswesty Disability Index, PEA proximal extension assay, TNF tumour necrosis factor alpha, $Y r$ years, VAS visual analogue scale

${ }^{\mathrm{a}}$ multivariate regression analysis

${ }^{b}$ no definition

cadjusted for age, sex, smoking, alcohol, body mass, use of diuretics and analgetic drugs and steroid injections during the previous $24 \mathrm{~h}$

${ }^{d}$ high pain group (VAS $>3$ )

e subgroup ruptured $A F$

was found for TNF-a in both serum $(\mathrm{r}=0,629)[27]$ and biopsy $(\mathrm{r}=0.65)$ [24]. For IL-8 in [2] and Il-6 in annulus fibrosis biopsy [27] low negative correlations were found: the presence of these markers is related to better clinical outcome. Moen et al. calculated an inflammation score (a weighted average of 41 protein scores) that was positive for all high pain patients $(\text { VAS }>40)^{287}$. Sturmer et al. showed that severe pain (VAS $>4$ ) is associated with increased hsCRP levels among patients with sciatica (adjusted $\mathrm{OR}=3.4(95 \% \mathrm{CI}, 1.1$ to 10) [23]. Corrections were made for age, sex, smoking and alcohol consumption. The prospective data of Pedersen et al. showed that levels IL-6 and IL-8 in serum were related to pain intensity measured on a VAS (IL-6, $\mathrm{F}(1.0,118)=9.7, p=0.002$ test of between subjects effect; IL-8, $\mathrm{F}(1.0,118.0)=6.9$, $p=0.01$ test of between subjects effect, rmANOVA, covariates age for IL-6; smoking for Il-6 and Il-8; and treatment for IL-8 [26]. In their multivariate analysis Schistadt el al showed that high levels of serum IL-6 correlated with high VAS for leg pain (beta score 0,64 ) and accounted for $25 \%$ of the variance in the VAS for leg pain at 1-year follow-up [15]. Schistadt et al. concluded that in addition to elevated Il-6 levels, intense pain, long surgery wait and low education are related to slow recovery [15]. The other studies did not give detailed information about the patients and their history in terms of education, work status, previous back surgery, comorbidity or the medication that was used.

\section{Discussion}

The studies under review were heterogeneous with regard to the population, the biomarkers that were studied and the laboratory methods that were used. For that reason pooling of data (meta-analysis) was impossible. The overall Risk of Bias (as assessed by the adapted QUIPS-tool) was moderate 9/12 studies; participation and measurement of the clinical outcome in particular were not optimal. Most frequently the VAS was used for the measurement of pain, but the studies did not accurately describe the location of the pain (back or leg) the 
reference point (i.e. time-window) or type of pain (for example average pain on activity or during the day). Therefore it is hard to draw firm conclusions, and although the strong positive correlation between IL-21 and pain in two studies [20,30], and the association between hsCRP levels and severe pain (VAS > 40) [23] might be of interest, they should be interpreted with great care.

\section{Strengths and limitations}

A strength of this study is the systematic and transparent approach that was followed in all the steps of this systematic review.

Still several biases can be introduced by literature search and selection procedure. First, due to selection bias relevant publications may have been missed. For example in our initial search we missed the relevant publication by Schistadt et al. [15]. Second, due to publication bias unpublished studies may have been missed. Third there might be reference bias: screening references may result in an over representation of positive studies, as trials with a negative result are less likely to be referred to.

Another limitation is that we used an adjusted version of the QUIPS-tool to asses ROB. We did not take into account the domains 'study confounding' and 'statistical analysis out'. We did not find relevant information in the literature to decide a-priori which confounders would be the most relevant in this field. Still, where possible, in the result section where we describe which factors were taken into account in the included studies. But unfortunately many studies no detailed information was included about other factors they took into account.

\section{Implications for practice}

The results of this review are not overly convincing which may suggest only a minor role for inflammation in sciatica. Of course this is based on limited data, however these results could potentially be interpreted in line with the results from therapeutic studies. There are two interventions in patients with sciatica, targeted at inflammation: 1) use of non steroidal anti inflammatory drugs (NSAIDs); 2) epidural injections with corticosteroids. The effects of both NSAIDs and injections seem to be minor.

A Cochrane review showed very low-quality evidence that the efficacy of NSAIDs for pain reduction is comparable with that of placebo and low-quality evidence that NSAIDs is better than placebo for global improvement [34].

With regard to effectivity of epidural corticosteroid injections a meta-analysis of 23 trials [35] showed a small positive short-term ( $<3$ months) effect for leg pain of epidural corticosteroid injections compared to placebo (mean difference (MD), -6.2 on a 100 points VAS) [95\% CI, 9.4 to -3.0$]$ ) and disability (MD, -3.1 on a 100 point Oswestry Disability Scale). A second meta-analysis of 30 trials [36] showed an immediate-term ( $<2$ weeks) pain reduction (MD -7.55 on a 100 point VAS [95\% CI, -11.4 to -3.74$]$ ) and reduction in disability (standardized MD, -0.33 [ $95 \% \mathrm{CI},-0.56$ to -0.09$]$ ) of epidural corticosteroid injections compared to placebo.

A potential explanation for a lack of treatment effect of both NSAIDs and epidural corticosteroid injections could be that inflammation plays a minor role in sciatica, or only plays an important role in a small subgroup of patients. Perhaps in the future we can identify patients with sciatica that respond well to both treatments for example acute patients (that were underrepresented in this systematic review) or patients with severe pain.

To summarize: though anti-inflammatory treatment (in the form of NSAIDs or epidural injections with corticosteroids) is the first choice of pain treatment in patients with sciatica, the evidence of inflammation playing a role in sciatica is not overly convincing based on laboratory studies.

\section{Implications for research}

The main question to be still answered here is if inflammation plays a role in lumbar radicular syndrome, at what stage and to what extent? From a research perspective, we think that the acute stage of sciatica (<12 weeks) deserves more attention given that the fact that although most patients recover within this period [37]. During the acute stage serum studies are relatively easy to perform. It is interesting to know what specific cytokines are elevated and if they have a prognostic value e.g. for chronicity. The markers that had high correlations with clinical measures in previous studies (for example Il-21) seem the most interesting candidates for further study. In addition we think that different laboratories should come to a consensus regarding the best method for measuring inflammation in sciatica.

In the nearby future inflammatory biomarkers could possibly predict the clinical course of sciatica and be used to identify subsets of patients that respond best to anti-inflammatory treatment (NSAIDs or epidural injections with corticosteroids) or patients that benefit from surgery.

\section{Conclusion}

In this systematic review there was considerable heterogeneity in the type of biomarkers and in the clinical measurements in the included studies. Taking into account the overall risk of bias of the included studies there is insufficient evidence to draw firm conclusions regarding the relationship between inflammation and clinical symptoms in patients with sciatica. 


\section{Additional files}

Additional file 1: The full search strategy for all databases. (DOCX 30 $\mathrm{kb})$

Additional file 2: Prisma Checklist for reporting in systematic reviews and meta-analyses. (DOC 62 kb)

Additional file 3: The Quality in Prognosis Studies Tool (QUIPS). (DOCX $17 \mathrm{~kb})$

\section{Abbreviations}

AF: Annulus fibrosus; aOR: Adjusted Odds ratio; Cl: Confidence interval: CSF: Cerebrospinal fluid; CXCM5: C-X-C motif chemokine 5; EGF: Epidermal growth factor; Elisa: Enzyme-linked immunosorbent assay; hsCRP: High sensitive C-reactive protein; IL: Interleukin; INFg: Interferon gamma; JOA: Japanese orthopedic association (score); LF: Ligamentum flavum; MCP 4: Monocyte chemotactic protein-4; mRNA qPCR: Messenger RNA qualitative polymerase chain reaction; NP: Nucleus pulposus; NSAIDS: Non-steroidal antiinflammatory drugs; ODI: Oswestry Disability Index; PEA: Proximal extension assay; Quips: Quality in prognosis studies; RCT: Randomized controlled trial; SF-36: Short form 36; VAS: Visual analogue scale

\section{Acknowledgements}

We thank Ms. Chantal den Haan MsC, librarian at the OLVG Hospital for her help with the database search.

\section{Funding}

None.

\section{Availability of data and materials}

Not applicable.

\section{Authors' contributions}

MJ, BTM and TVO carried out data collection and analysis. MJ and BTM designed the study. BTM made revisions after comments from the editors. $\mathrm{RO}$ and $\mathrm{HW}$ are the principal investigators. All authors read and corrected draft versions of the manuscript and approved the final manuscript.

\section{Ethics approval and consent to participate}

"Not applicable" (literature study).

\section{Consent for publication}

"Not applicable" as our manuscript does not contain any individual person's data in any form.

\section{Competing interests}

The authors declare that they have no competing interests.

\section{Publisher's Note}

Springer Nature remains neutral with regard to jurisdictional claims in published maps and institutional affiliations.

\section{Author details \\ ${ }^{1}$ Department of Neurology, OLVG, Amsterdam, The Netherlands. ${ }^{2}$ Department of Neurology, Zaans Medisch Centrum, Zaandam, The Netherlands. ${ }^{3}$ Department of Health Sciences, VU University, De Boelelaan, 1081 Amsterdam, HV, Netherlands. ${ }^{4}$ Department of Epidemiology and Biostatistics and the Amsterdam Movement Sciences Research Institute, Amsterdam UMC, De Boelelaan, 1081 Amsterdam, HV, Netherlands.}

Received: 26 October 2018 Accepted: 28 March 2019

Published online: 09 April 2019

\section{References}

1. Ropper AH, Zafonte RD. Sciatica. N Engl J Med. 2015;372(13):1240-8. https:// doi.org/10.1056/NEJMra1410151. Review. No abstract available. PMID: 25806916 .

2. Spijker-Huiges A, Groenhof F, Winters JC, van Wijhe M, Groenier KH, van der Meer K. Radiating low back pain in general practice: incidence, prevalence, diagnosis, and long-term clinical course of illness. Scand J Prim Health Care. 2015;33(1):27-32

3. Lambeek LC, van Tulder MW, Swinkels IC, Koppes LL, Anema JR, van Mechelen W. The trend in total cost of back pain in the Netherlands in the period 2002 to 2007. Spine (Phila Pa 1976). 2011;36(13):1050-8.

4. Porchet F, Wietlisbach V, Burnand B, Daeppen K, Villemure JG, Vader JP. Relationship between severity of lumbar disc disease and disability scores in sciatica patients. Neurosurgery. 2002:50:1253-1259.5.

5. El Barzouhi A, Vleggeert-Lankamp CL, Nijeholt GJ LÀ, Van der Kallen BF, van den Hout WB, Jacobs WC, Koes BW, Peul WC, Leiden-The Hague Spine Intervention Prognostic Study Group. Magnetic resonance imaging in follow-up assessment of sciatica. N Engl J Med. 2013;368(11):999-1007.

6. Khan AN, Jacobsen HE, Khan J, Filippi CG, Levine M, Lehman RA Jr, Riew KD, Lenke LG, Chahine NO. Inflammatory biomarkers of low back pain and disc degeneration: a review. Ann N Y Acad Sci. 2017;1410(1):68-84. https://doi. org/10.1111/nyas.13551 Review.

7. Wuertz K, Haglund L. Inflammatory mediators in intervertebral disk degeneration and discogenic pain. Global Spine J. 2013;3(3):175-84.

8. Podichetty VK. The aging spine: the role of inflammatory mediators in intervertebral disc degeneration. Cell Mol Biol (Noisy-le-grand). 2007:53(5):4-18.

9. Baron R, Binder A. Et. al. neuropathic low back pain in clinical practice. Eur J Pain. 2016;20(6):861-73.

10. Moher D, Liberati A, Tetzlaff J, Altman DG; The PRISMA Group. Preferred reporting items for systematic reviews and meta-analyses: the PRISMA statement. PLoS Med. 2009;6(6):e1000097. www.prisma-statement.org.

11. Hayden JA, van der Windt DA, Cartwright JL, Côté P, Bombardier C. Assessing bias in studies of prognostic factors. Ann Intern Med. 2013;158(4):280-6.

12. Den Bakker CM, Anema JR, Zaman AGNM, de Vet HCW, Sharp L, Angenete E, Allaix ME, Otten RHJ, Huirne JAF, Bonjer HJ, de Boer AGEM, Schaafsma FG. Prognostic factors for return to work and work disability among colorectal cancer survivors; a systematic review. PLoS One. 2018;13(8):e0200720.

13. Hinkle DE, Wiersma W, Jurs SG. Applied statistics for the behavioral sciences. 5th ed. Boston: Houghton Mifflin; 2003.

14. Chen $\mathrm{H}$, Cohen $\mathrm{P}$, Chen $\mathrm{S}$. How big is a big odds ratio? Interpreting the magnitudes of odds ratios in epidemiological studies. Communications in Statistics - Simulation and Computation. 2010;39(4):860-4.

15. Schistad El, Espeland A, Pedersen LM, Sandvik L, Gjerstad J, Røe C. Association between baseline IL-6 and 1-year recovery in lumbar radicular pain. Eur J Pain. 2014;18(10):1394-401.

16. Piperno M, Hellio le Graverand MP, Reboul P, Mathieu P, Tron AM, Perrin G, Peschard MJ, Richard M, Vignon E. Phospholipase A2 activity in herniated lumbar discs. Clinical correlations and inhibition by piroxicam. Spine (Phila Pa 1976). 1997;22(18):2061-5.

17. Brisby H, Olmarker K, Larsson K, Nutu M, Rydevik B. Proinflammatory cytokines in, cerebrospinal fluid and serum in patients with disc herniation and sciatica. Eur Spine J. 2002;11(1):62.

18. Sugimori K, Kawaguchi Y, Morita M, Kitajima I, Kimura T. High-sensitivity analysis of serum C-reactive protein in young patients with lumbar disc herniation. J Bone Joint Surg Br. 2003;85(8):1151-4.

19. Cheng L, Fan W, Liu B, Wang X, Nie L. Th17 lymphocyte levels are higher in patients with ruptured than non-ruptured lumbar discs, and are correlated with pain intensity. Injury. 2013;44(12):1805-10 2013.

20. Xue $H$, Yao Y, Wang $X$, Zhang F, Jiang X, Liu J, Wang H, Li Y, Wang X, Li H, Zhang J. Interleukin-21 is Associated with the Pathogenesis of Lumbar Disc Herniation. Iran J Allergy Asthma Immunol. 2015:14(5):509-18.

21. Peng ZY, Chen R, Fang ZZ, Chen B, Wang ZH, Wang XY. Increased local expressions of CX3CL1 and CCL2 are related to clinical severity in lumbar disk herniation patients with sciatic pain. J Pain Res. 2017;10:157-16.

22. Palada V, Ahmed AS, Finn A, Berg S, Svensson Cl, Kosek E. Characterization of euroinflammation and periphery-to-CNS inflammatory cross-talk in patients with disc herniation and degenerative disc disease. Brain Behav Immun. 2019;75:60-71.

23. Stürmer T, Raum E, Buchner M, Gebhardt K, Schiltenwolf M, Richter W, Brenner $H$. Pain and high sensitivity $C$ reactive protein in patients with chronic low back pain and acute sciatic pain. Ann Rheum Dis. 2005;64(6):921-5.

24. Andrade P, Hoogland G, Teernstra OP, van Aalst J, van Maren E, Daemen MA, Visser-Vandewalle V. Elevated IL-1 $\beta$ and IL-6 levels in lumbar herniated discs in patients with sciatic pain. Eur Spine J. 2013;22(4):714-20.

25. Andrade P, Visser-Vandewalle V, Philippens M, Daemen MA, Steinbusch HW, Buurman WA, Hoogland G. Tumor necrosis factor-a levels correlate with postoperative pain severity in lumbar disc hernia patients: opposite clinical 
effects between tumor necrosis factor receptor 1 and 2. Pain. 2011;152(11): 2645-52.

26. Pedersen LM, Schistad E, Jacobsen LM, Røe C, Gjerstad J. Levels of the proinflammatory interleukins 6 (IL-6) and -8 (IL-8) in patients with lumbar radicular pain due to disc herniation: a 12-month prospective study. Brain Behav Immun. 2015;46:132-6.

27. Wang K, Bao JP, Yang S, Hong X, Liu L, Xie XH, Wu XT. A cohort study comparing the serum levels of pro- or anti-inflammatory cytokines in patients with lumbar radicular pain and healthy subjects. Eur Spine J. 2016;25(5):1428-34 1.

28. Moen A, Lind AL, Thulin M, Kamali-Moghaddam M, Røe C, Gjerstad J, Gordh T. Inflammatory serum protein profiling of patients with lumbar radicular pain one year after disc herniation. Int J Inflam. 2016;2016:3874964.

29. Zu B, Pan H, Zhang XJ, Yin ZS. Serum levels of the inflammatory cytokines in patients with lumbar radicular pain due to disc herniation. Asian Spine J. 2016;10(5):843-9.

30. Chen B, Liu Y, Zhang Y, Li J, Cheng K, Cheng L. IL-21 is positively associated with intervertebral disc degeneration by interaction with TNF-a through the JAK-STAT signaling pathway. Inflammation. 2017;40(2):612-22.

31. Kraychete DC, Sakata RK, Issy AM, Bacellar O, Santos-Jesus R, Carvalho EM. Serum cytokine levels in patients with chronic low back pain due to herniated disc: analytical cross-sectional study. Sao Paulo Med J. 2010;128(5):259-62.

32. Weber KT, Alipui DO, Sison CP, Bloom O, Quraishi S, Overby MC, Levine M, Chahine NO. Serum levels of the proinflammatory cytokine interleukin-6 vary based on diagnoses in individuals with lumbar intervertebral disc diseases. Arthritis Res Ther. 2016;18:3.

33. Xiaogang M, Quanshan H, Liping Z, Kaken H. The expression of cytokine and its significance for the intervertebral disks of Kazakhs. J Clin Lab Anal. 2017;31(5). https://www.ncbi.n/m.nih.gov/pubmed/27807886.

34. Rasmussen-Barr E, Held U, Grooten WJ, Roelofs PD, Koes BW, van Tulder MW, Wertli MM. Nonsteroidal anti-inflammatory drugs for sciatica: an updated Cochrane review. Spine (Phila Pa 1976). 2017;42(8):586-94.

35. Pinto RZ, Maher CG, Ferreira ML, Hancock M, Oliveira VC, McLachlan AJ, Koes B, Ferreira PH. Epidural corticosteroid injections in the management of sciatica: a systematic review and meta-analysis. Ann Intern Med. 2012;157:865-77.

36. Chou R, Hashimoto R, Friedly J. Epidural corticosteroid injections for radiculopathy and spinal stenosis: A Systematic Review and Meta-analysis. Ann Intern Med. 2015:163(5):373-81.

37. Vroomen PC, de Krom MC, Wilmink JT, Kester AD, Knottnerus JA. Lack of effectiveness of bed rest for sciatica. N Engl J Med. 1999;340:418-23.

Ready to submit your research? Choose BMC and benefit from:

- fast, convenient online submission

- thorough peer review by experienced researchers in your field

- rapid publication on acceptance

- support for research data, including large and complex data types

- gold Open Access which fosters wider collaboration and increased citations

- maximum visibility for your research: over $100 \mathrm{M}$ website views per year

At $\mathrm{BMC}$, research is always in progress.

Learn more biomedcentral.com/submissions 